Reprinted from

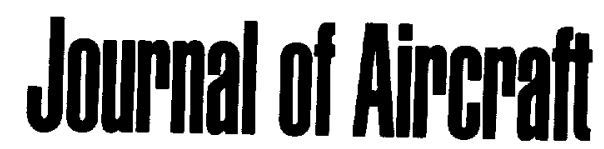

Volume 32, Number 5, Pages 1072-1078

OA/A

A publication of the

American Institute of Aeronautics and Astronautics, Inc.

370 L'Enfant Promenade, SW

Washington, DC 20024-2518 


\title{
Experimental Study of Lift-Enhancing Tabs on a Two-Element Airfoil
}

\author{
Bruce L. Storms* \\ Sterling Software, Palo Alto. California 94303 \\ and \\ James C. Rosst \\ NASA Ames Research Center, Moffett Field, California 94035-1000
}

\begin{abstract}
The results of a wind-tunnel test are presented for a two-dimensional NACA $63_{2}-215$ Mod B airfoil with a $30 \%$ chord single-slotted flap. The use of lift-enhancing tabs (similar to Gurney flaps) on the lower surface near the trailing edge of both elements was investigated on four flap configurations. A combination of vortex generators on the fap and lift-enhancing tabs was also investigated. Measurements of surface-pressure distributions and wake profiles were used to determine the aerodynamic performance of each configuration. By reducing flow separation on the flap, a lift-enhancing tab at the main-element trailing edge increased the maximum lift by separ $3 \%$ for the 42 -deg flap case. The tab had a lesser effect at a moderate flap deflection ( $32 \mathrm{deg}$ ) and adversely affected the performance at the smallest flap deflection $(22 \mathrm{deg})$. A tab located near the fap trailing edge produced an additional lift increment for all nap deflections. The application of vortex generators to the flap eliminated lift-curve hysteresis and reduced flow separation on two configurations with large flap deflections $1>40 \mathrm{deg}$. A maximum-lift coefficient of $3.32(17 \%$ above the optimum baseline) was achieved with the combination of lift-enhancing tabs on both elements and vortex generators on the hap.
\end{abstract}

\section{Nomenclature}

$c_{1}=$ section drag coefficient, $d / q c$

$C_{1}=$ section lift coefficient. $/ / q \mathrm{c}$

$C_{m}=$ section pitching-moment coefficient. $m / q c^{2}$

$C_{l}=$ pressure coefficient. $(p-p) /$.

$\therefore$ = reference airfoil chord

$d=$ section drag

$d=$ distance from tab to trailing edge

$g \quad=$ flap gap

$h=$ height

$L / D=$ lift-to-drag ratio

$1=$ section lift

$m$ = section pitching moment

$o l=$ flap overlap

D = static pressure

$q=$ dynamic pressure, $1 / 2 p V^{2}$

Re $=$ Reynolds number

$V=$ freestream velocity

$=$ angle of attack

$=$ deflection angle

$=$ density of air

Subscripts

$f=$ flap

$\max =$ maximum value

$x=$ freestream value

Presented as Paper 94-1868 at the AIAA 12th Applied Aerody namics Conference. Coloriado Springs, CO, Junc 20-23, 1994; received Sept. 27. 1994: revision received March 17, 1995; accepted for publication March 27. 1995. Copyright 01995 by the American Institute of Acronautics and Astronautics, Inc. All rights reserved.

*Aerospace Engineer, Low-Speed Aerodynamics Branch. M/S 2472. NASA Ames Research Center. Member AIAA.

tAerospace Enginecr. Low-Speed Acrodynamics Branch, M/S 2472. NASA Ames Research Center. Senior Member AlAA

\section{Introduction}

$\mathbf{T}$ HE performance and complexity of modern high-lift systems are increasingly important in the design of subsonic transport aircraft. In addition to limiting payload. the highlift performance greatly influences the cruise-wing design. The hest performance has traditionally been achieved with highlift systems that use double- or triple-slotted flaps. However, the complexity of these designs carries significant weight penalties and requires high maintenance. Current design efforts have focused on mechanically simpler high-lift systems that incorporate advanced technology to provide increased performance.

Valarezo et al.' reported the effects of a drooped spoiler and trailing-edge wedges on the performance of an advanced three-element airfoil. By deflecting the spoiler 5 and $10 \mathrm{deg}$ downward. the lift was consideribly increased at the lower angles of attack. However, both the maximum-lift coefficient and stall angle were reduced with the drooped spoiler. To study the effects of a small $(3 \% \mathrm{c})$ split flap (n the high-lift performance, wedges with included angles from 15 to 60 deg were applied to the flap trailing edge. The wedges provided a lift increment that decreased with angle of attack and yielded a marginal increment in the maximum-lift coefficient $(0.07$ for al 45 -deg wedge). The lift increment was attributed to the augmented loading of the main element due to the increased upwash from the flap.

The effects of the trailing-edge wedge are similar to those of the Gurnev flap as first presented hy Liebeck. ' Originally applied to race-car airfoils used to generate down force. the Gurney flap is a small tab $(<5 \%$ c) located perpendicularly to the pressure side of the airfoil at the trailing edge. The Gurney flap has been tested on various single-element airfoils" " where it is shown to provide considerable lift enhancement. In general, the lift increment increases with flap height, but the lift-to-drat ratio $L D D$ is decreased for flap heights greater than about $1.5 \% \mathrm{c}$. Other researchers studied the effects of a $5 \%$ c Gurney flap on the trailing element of multielement airfoils for race cars. Wind-tunnel results indicate that the maximum lift is significantly in- 
creased while $l / D$ is decreased relative to the baseline airfoil (no Gurney flap)

Lift-enhancing tabs" are a variation of the Gurney flap wherein the tab may be placed on any element of a multiclement airfoil. The tabs can also be located forward of the trailing edge to facilitate their deployment without adversely affecting the aerodynamic performance. In the two-element application reported in Ref. 9. the tab was placed in the trailing-edge cove of a NACA $63,-215$ Mod B airfoil with a $30 \%$ single-slotted flap. Both experimental and computational results were presented for one flap rigging with a 4.3 deg flap deflection. The experiment validates the companion Navier-Stokes computations that provide insight into the flow mechanisms associated with the lift-enhancing tab. "By turning the flow toward the flap and reducing its effective angle of attack. the tab eliminates significant flow separation and increases the loading of both the flap and main element.

In addition to the one configuration presented in Ref. 9. this article details three other flap configurations with varied gap. overlap, and tlap deflection. The use of lift-enhancing tabs was tested on both elements with flap deflections ranging from 22 to $4.3 \mathrm{deg}$. The effects of tab size and location wero studied for a lift-enhancing tab near the main-element trailing edge. Only one tab size and location was tested on the flap. The effect of applying wishbone vortex generators" to the flap upper surface was also studied on two of the four configurations.

\section{Experimental Setup}

The experiment was conducted in the 7 by $10 \mathrm{ft}$ Wind Tunnel no. 2 at the NASA Ames Research Center. This facility is a closed-circuit wind tumnel incorporating a 15 -ft-long test section with a constant height of $7 \mathrm{ft}$ and a width of $10 \mathrm{ft}$ with a $1 \%$ divergence. There are no turbulence-reducing screens in the circuit and the test-section turbulence intensity level is $1.0 \%$ at $225 \mathrm{ft} / \mathrm{s}$. All data was obtained at a chord Reynolds number of approximately $3.7 \times 10^{\prime \prime}$

The two-dimensional airfoil consisted of a NACA 63,-215 Mod $B^{\prime 2}$ main element and a $30 \%$ slotted flap. Mounted vertically between two false walls, the model had a span of 5 $\mathrm{ft}$ and a clean (flap stowed) airfoil chord of $2.5 \mathrm{ft}$ (Fig. 1). On the main element, boundary-layer trip strips were placed at 5 and $10 \%(6$ on the upper and lower surfaces, respectively. The model was instrumented with a total of 159 pressure taps divided into three chordwise rows located at midspan and one-sixth span from the wall on either side. The midspan row contained 73 pressure taps with the remaining taps divided equally between the other two rows. The lift-and pitchingmoment coefficients were determined by an integration of the centerline pressure distribution while the additional rows of pressure taps were used to monitor the two dimensionality of the flow.

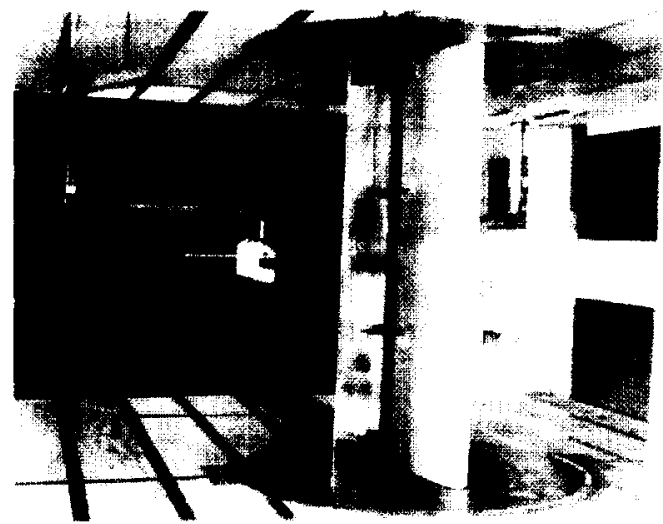

Fig. 1 NACA 63,-215 Mod $B$ airfoil model in the 7 by $10 \mathrm{ft}$ wind tunnel.

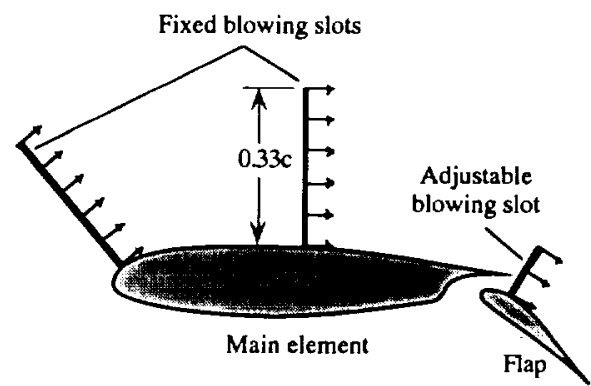

Fig. 2 Side-wall boundary-layer control slots.

NACA $63_{2}-215$ Mod B airfoil

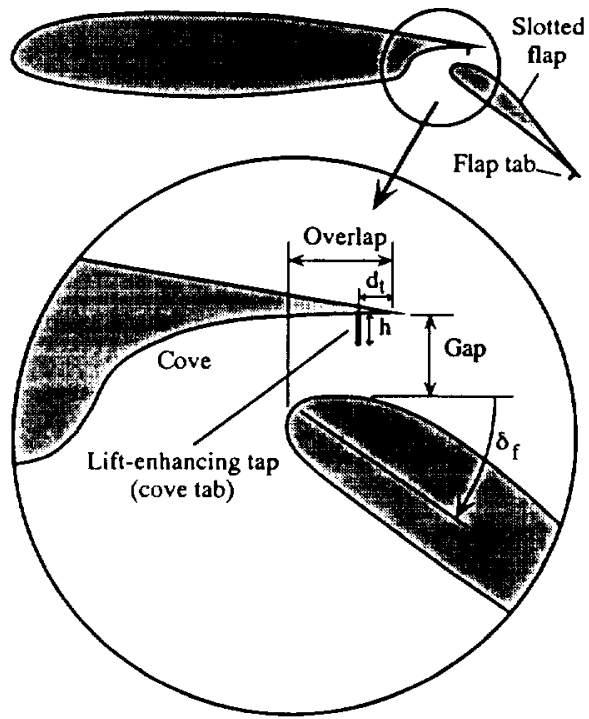

Fìg. 3 Lift-enhancing tabs on a two-element airfoil.

A side-wall boundary-layer control (BLC) system (Fig. 2) provided blowing along the false walls to promote two-dimensional flow on this low AR model. Two fixed blowing slots were located at the leading edge and at midchord of the main element while a smaller adjustable blowing slot was located above the flap-upper surface. The adjustable slot was rotated to achieve tangential blowing at the airfoil surface for each flap deflection. With sidewall BLC, the three chordwise pressure distributions indicated two-dimensional flow for all angles of attack up to the maximum-lift condition.

The drag coefficient was determined by an integration of the static and total pressures measured by a wake rake situated $0.7 c$ downstream of the flap trailing edge. The Bet $z^{1:}$ integration scheme was used to account for the variation of static pressure due to flow curvature typical of high-lift airfoils. The rake was composed of 91 total and 9 static pressure probes distributed over $3 \mathrm{ft}$ with clustering near the rake centerline. A motor-driven traverse was used to center the rake horizontally on the airfoil wake at the midspan location. Both the rake and surface pressures were measured with an electronically scanned pressure system for rapid data acquisition. All aerodynamic coefficients are reported in the wind-axis system and the pitching moment is computed about the $1 / 4 \mathrm{c}$ location.

The repeatability of the lift coefficient measurements was +0.02 for $C_{1} \leq 0.9 \times C_{\text {mix }}$ and \pm 0.04 for $C_{1}>0.9 \times C_{\text {mix }}$. Likewise. the repeatability of the drag coefficient measurements was $\pm 0.0\left(05\right.$ for $C_{t} \leq 0.9 \times C_{1}, \pm 0.010$ for $0.9 \times$ $C_{\text {max }}<C_{1} \leq C_{\text {imix }}$, and \pm 0.020 beyond $C_{l \text { ax }}$. These error bands include both measurement resolution and point-to-point repeatability that result in a maximum uncertainty of $+5 \%$. in the $l / D$ ) ratios. 
Table I Two-element airfoil configurations tested

\begin{tabular}{cccc}
\hline & $\begin{array}{c}\text { Flap } \\
\text { deflection. } \\
\text { deg }\end{array}$ & Gap/c & Overlap/c \\
\hline 1 & 22 & 0.020 & 0.066 \\
2 & 32 & 0.031 & 0.043 \\
3 & 43 & 0.031 & 0.042 \\
4 & 42 & 0.052 & 0.035 \\
\hline
\end{tabular}

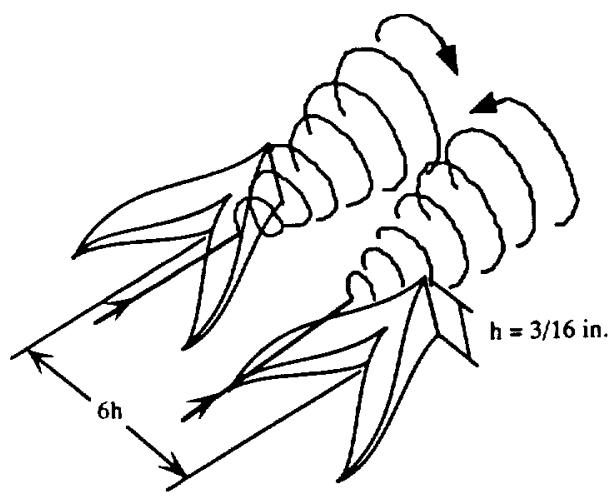

Fig. 4 Wishbone-type vortex generators tested on the flap upper surface.

In a previous unpublished study of the same two-element airfoil, 35 different configurations were tested in a parametric variation of gap, overlap, and flap deflection. From this test matrix, four near-optimum configurations were chosen for the present study. The flap rigging parameters of these configurations are listed in Table 1.

The devices tested on this airfoil include the lift-enhancing tab and vortex generators. The application of the lift-enhancing tab is shown in Fig. 3 along with the relevant flaprigging parameters. This device is essentially a flat plate mounted perpendicularly to the pressure side of the airfoil near the main-element and/or flap trailing edge. Two tab heights of 0.5 and $1 \%$ ce were studied at or near the trailing edge of the flap cove on the main element. A $0.5 \% \mathrm{c}$ tab was tested on the flap. The lift-enhancing tab in these two positions will be referred to as a cove tab and flap tab, respectively. The wishbone-type vortex generators (Fig. 4) measured $3 / 16$ in. in height and were located on the upper surface of the flap at $10 \%$ flap chord. They were distributed evenly across the span with six device heights between centers.

\section{Results and Discussion}

Two corrections were applied to the experimental data. The most significant correction accounted for the induced effects of the airfoil on the static pressure measured by the pitotstatic probe. To correct the airfoil pressure coefficients (computed using the probe static pressure), a panel method was employed to determine the static-pressure variation at the probe location as a function of lift coefficient. The second correction represents the increased angle of incidence induced by the presence of the wind-tunnel walls. In this case, the panel method was used to determine the effective angle of incidence with and without walls for a given lift condition. These corrections were applied to facilitate comparisons with results from computational fluid dynamics. The test-section blockage was $11.6 \%$ at an angle of attack of $12 \mathrm{deg}$ (maximum lift).

The cove tab was tested at two locations on the main element: 1) at the trailing edge and 2) at an inboard position, one tab height forward of the trailing edge. The flap tab was tested at the inboard position where the location of a hinge line would be more practical. Except where noted, the data presented is for the inboard tab position $\left(d_{t} / c=h / c\right)$, which will subsequently be shown to be the most effective location. The following results refer to the configurations listed in Table 1.

\section{Configuration No. 1}

This flap rigging is representative of a takeoff configuration designed for a high $L / D$ at moderate lift coefficients. The pressure distributions of the baseline and cove-tab cases are presented in Fig. 5 at an angle of attack of $10 \mathrm{deg}$. The baseline data indicates attached flow over the flap while the addition of a $0.5 \% \mathrm{c}$ cove tab tends to destroy the suction peak near the flap leading edge. The reduced flap effectiveness with the tab also leads to reduced suction along the upper surface of the main element. The resulting lift curve and drag polar (Fig. 6) indicate reduced lift and increased drag for the cove-tab configuration relative to the baseline.

When a lift-enhancing tab is placed on the flap (with no cove tab), the lift curve is shifted so that the angle of attack for a given lift coefficient is reduced. Also, the maximum-lift coefficient is increased by $4 \%$ while the drag is marginally increased at the lower angles of attack. An analysis of lift coefficient by element (Fig. 7) reveals that most of the lift increment is generated by the main element. Although the lift of the flap is also increased, the upwash from the flap augments the loading of the main element whose lift contribution is larger due to its relative size and orientation. This result was also noted for trailing-edge wedges in Ref. 1.

\section{Configuration No. 2}

This configuration incorporates a moderate flap deflection as is commonly employed during approach. The baseline pressure distribution at an angle of attack of 10 deg (Fig. 8) indicates flow separation on the flap at approximately $25 \% \mathrm{c}$ (note flat region aft of the suction peak). The addition of a $0.5 \%$ c cove tab again reduces the flap suction peak as was noted in the previous configuration. This allows the downstream flow to remain attached and results in increased aft loading of the main element as well as a higher suction peak.

The overall effect of the cove tab on lift and drag is shown for cove-tab heights of 0.5 and $1 \% c$ in Fig. 9. Both tabs significantly increase lift at moderate angles of attack and reduce the angle of incidence for maximum lift. In addition, the cove tab reduces drag on this configuration by maintaining attached flow on the flap. For the $0.5 \% \mathrm{c}$ tab, the lift curve is shifted by approximately $4 \mathrm{deg}$ at low angles of attack and the maximum-lift coefficient is increased by $4.1 \%$. The addition of a $0.5 \% \mathrm{c}$ flap tab provides an added lift increment $\left(0.04\right.$ at $\left.C_{r_{\max }}\right)$ while the drag is marginally increased relative to the cove-tab-only configuration.

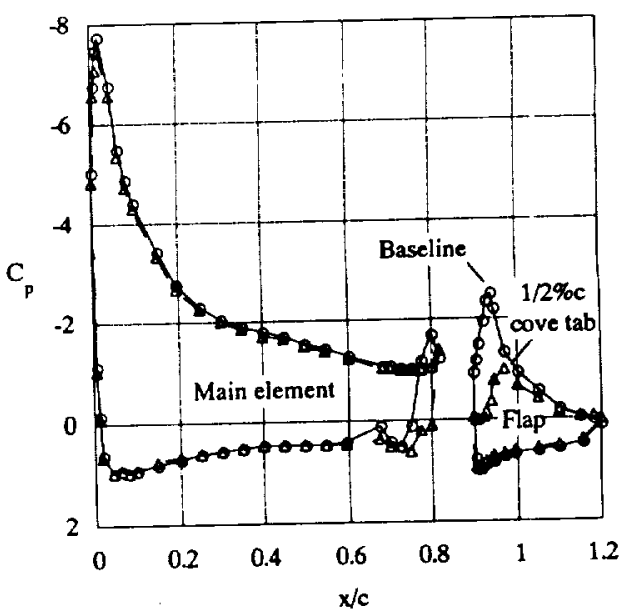

Fig. 5 Effect of $1 / 2 \% c$ cove tab on pressure distributions at $\alpha=10$ deg (configuration 1). 

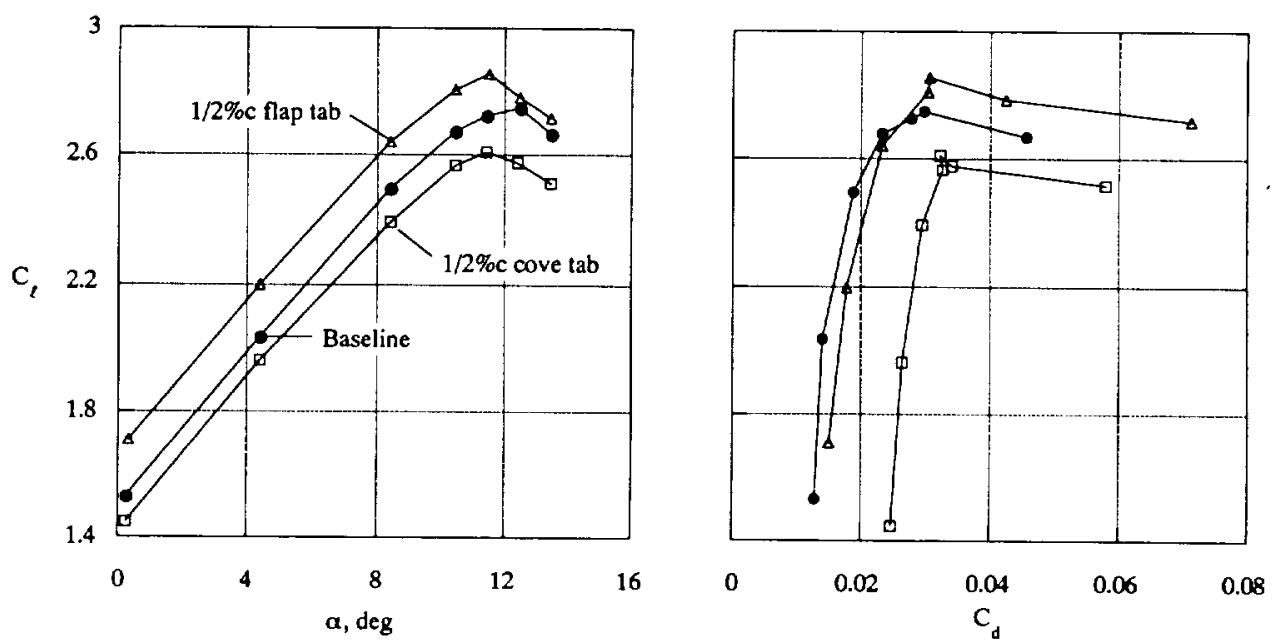

Fig. 6 Effect of lift-enhancing tabs on lift curve and drag polar (configuration 1).

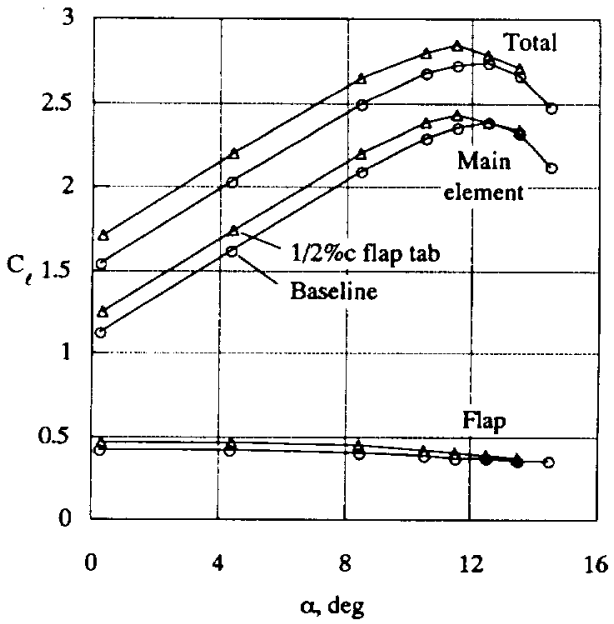

Fig. 7 Effect of $1 / 2 \% c$ flap tab on lift coefficient (configuration 1 ).

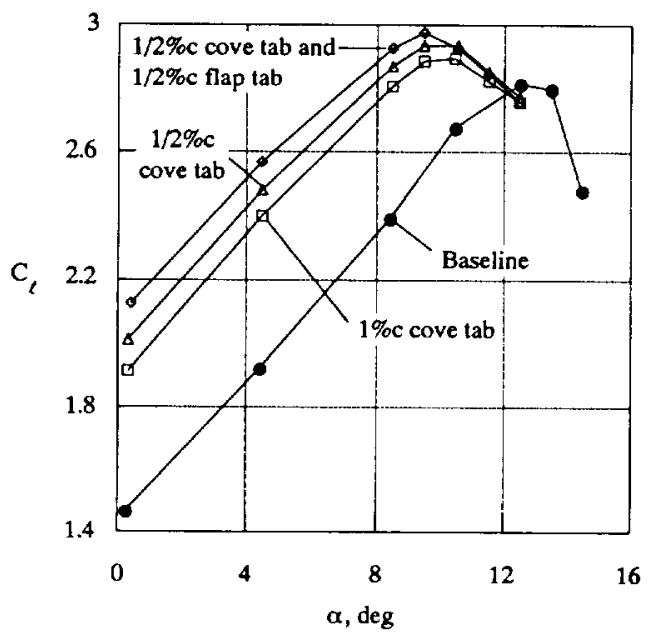

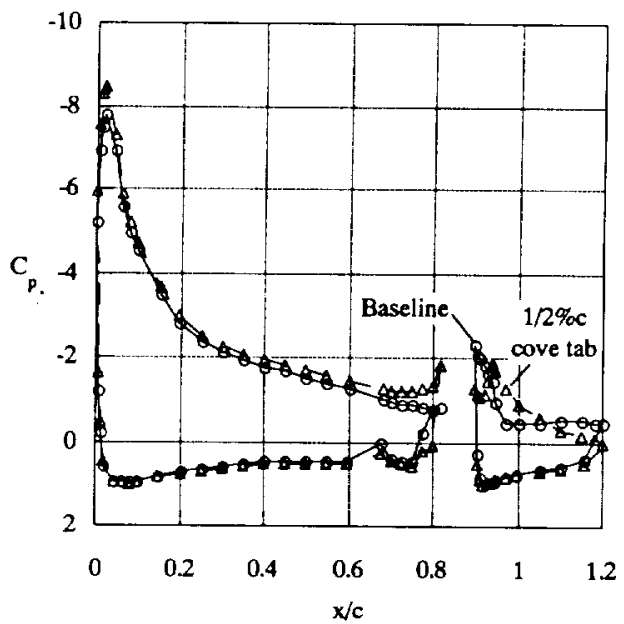

Fig. 8 Effect of $1 / 2 \% c$ cove tab on pressure distributions at $\alpha=10$ deg (configuration 2).

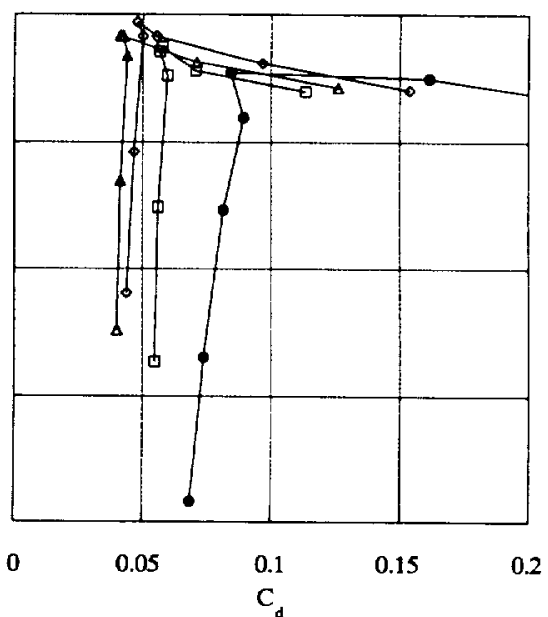

Fig. 9 Effect of lift-enhancing tabs on lift and drag coefficients (configuration 2).

Additional flow features are evident in an analysis of lift coefficient by element (Fig. 10). As noted for the flap tab, most of the cove-tab lift increment is generated by the main element and not the flap. Also, the flap loading indicates an increased effectiveness of the baseline flap near maximum lift. The pressure distributions (not shown) indicate attached flow on the flap for angles of attack above $10 \mathrm{deg}$. The attached flow on the flap also increases the main-element load- ing and yields a maximum-lift coefficient of 2.82 . This value is the highest of all four baseline (no tab) configurations tested

\section{Configuration No, 3}

This flap rigging is representative of a landing configuration with a large flap deflection to achieve high maximum lift. At an angle of attack of $8 \mathrm{deg}$, the baseline pressure distribution (Fig. 11) indicates separated flow closer to the leading edge 


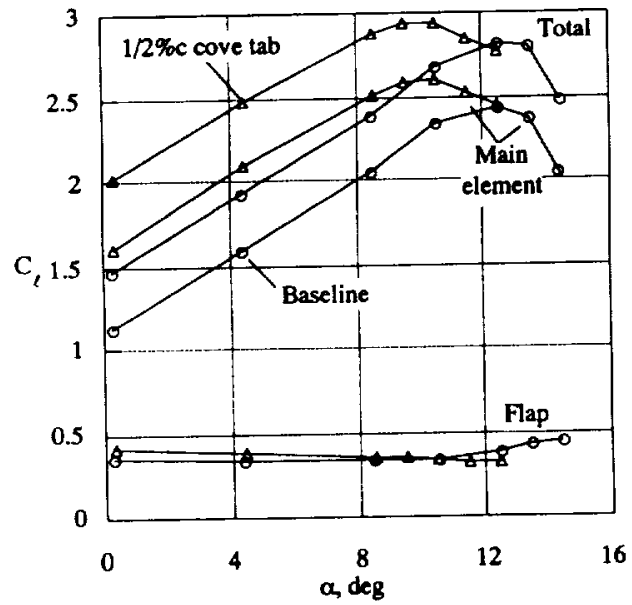

Fig. 10 Effect of $1 / 2 \% c$ cove tab on lift coefficient (configuration 2).

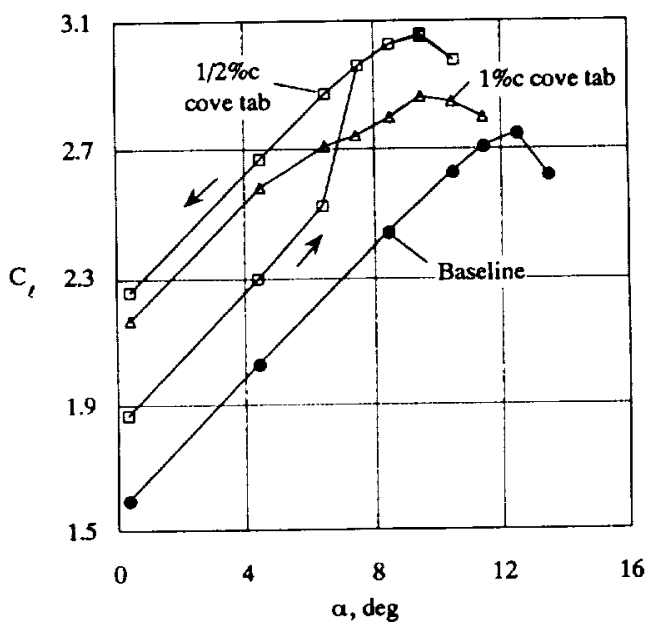

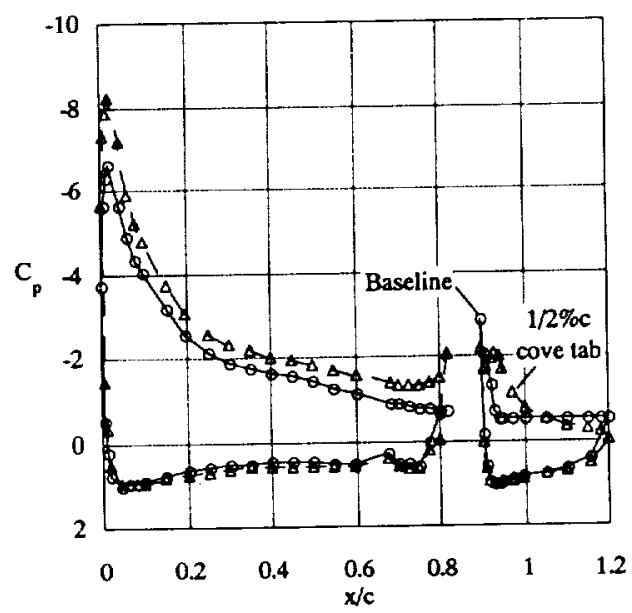

Fig. 11 Effect of $1 / 2 \% c$ cove tab on pressure distributions at $\alpha=8$ deg (configuration 3).

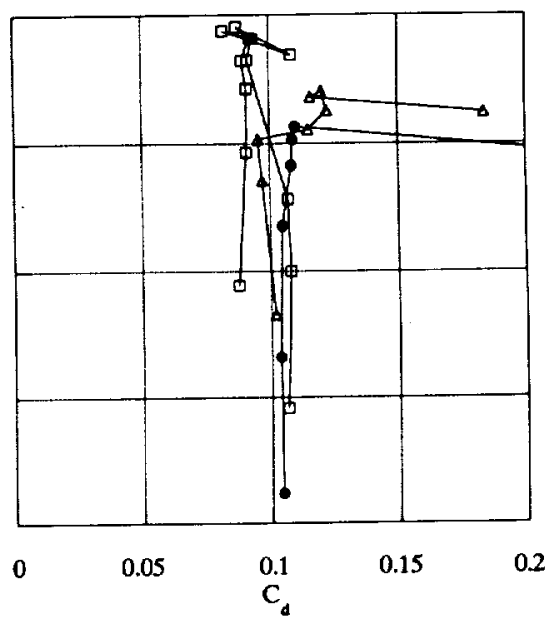

Fig. 12 Effect of lift-enhancing tabs on lift curve and drag polar (configuration 3 ).

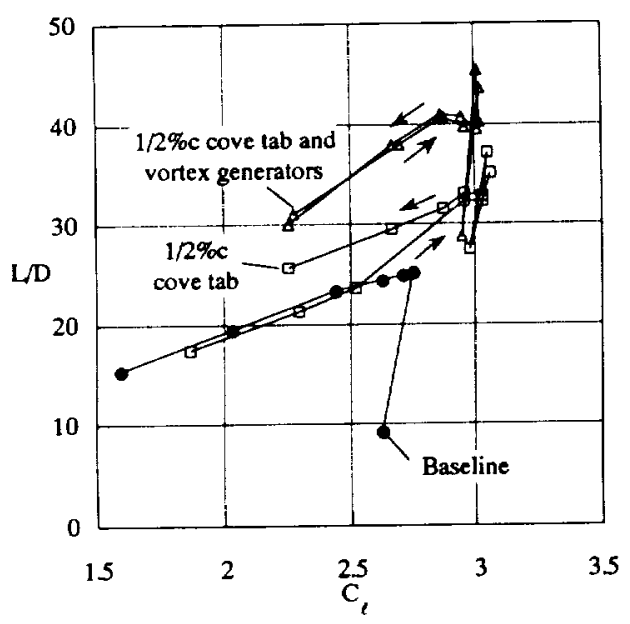

Fig. 13 Effect of cove tab and vortex generators on $L / D$ ratio (configuration 3).

than was illustrated on the previous configuration. With a $0.5 \% \mathrm{c}$ cove tab, however, the suction peak on the flap is reduced allowing the boundary layer to negotiate the adverse pressure gradient without separation. This results in increased loading of the main element especially near the trailing edge.

The lift curve and drag polar for the 0.5 and $1 \% c$ cove tabs (Fig. 12) indicate that the smaller tab is more effective on this configuration, yielding a $10.3 \%$ increase in maximum lift.

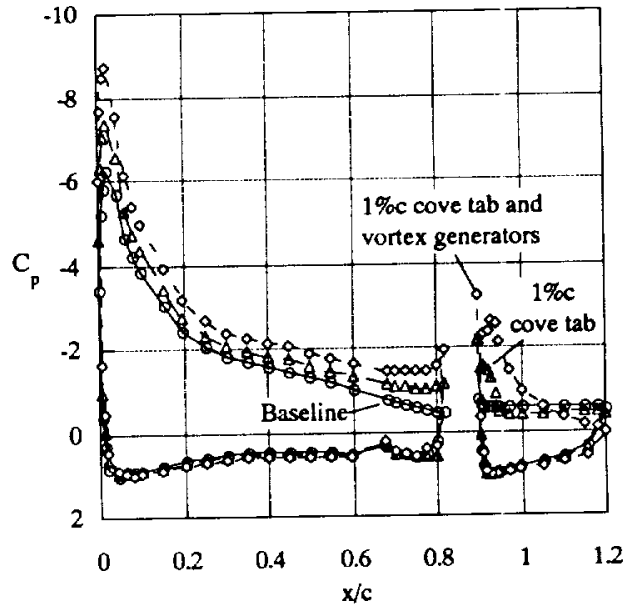

Fig. 14 Effect of cove tab and vortex generators on pressure distributions at $\alpha=8 \mathrm{deg}$ (configuration 4).

However, strong hysteresis is noted at lou angles of attack for the smaller tab as indicated by the two branches of the lift curve. In this configuration, the flow over the flap separates near the leading edge until the angle of attack is increased to approximately $8 \mathrm{deg}$ when reattachment occurs. However, when the angle of attack is decreased from the maximum-lift condition, the flow over the flap remains attached. 

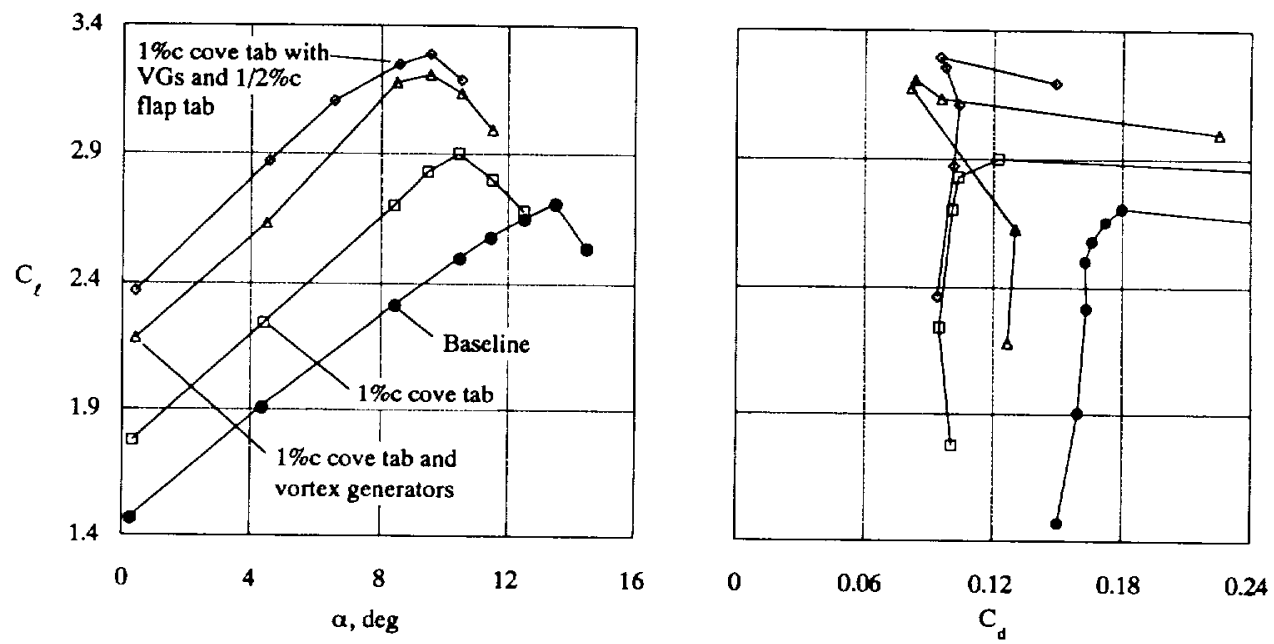

Fig. 15 Effect of lift-enhancing tabs and vortex generators on lift and drag coefficients (configuration 4).

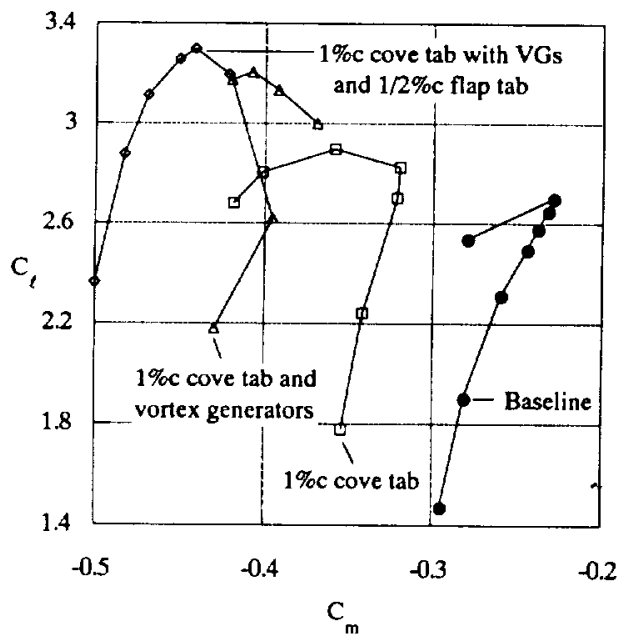

Fig. 16 Effect of lift-enhancing tabs and vortex generators on pitching moment (configuration 4).

To avoid this undesirable phenomenon, wishbone vortex generators were placed on the flap upper surface at $10 \% \mathrm{c}$. At this position on a typical transport aircraft, they would be concealed during cruise averting a drag penalty. As illustrated by the $L / D$ curve (Fig. 13), the result is to effectively eliminate hysteresis with a negligible change in lift and a reduction in drag. Compared with the cove-tab-only case, the vortex generators increase the maximum $L / D$ by $22 \%$. Since the pressure distributions are essentially identical with and without vortex generators, this effect is attributed to the reduction or elimination of an off-body recirculation region alluded to in Ref. 9. Off-body recirculation is sometimes present in multielement aerodynamics when the wake of one element is unable to negotiate the adverse pressure gradient along its path above the next element. ${ }^{1.1}$

\section{Configuration No. 4}

This flap rigging is similar to that of the previous configuration with a significantly increased gap and a reduced overlap. The effect of a $1 \%$ c cove tab and vortex generators as compared with the baseline is illustrated in the pressure distributions at an angle of attack of 8 deg (Fig. 14). Due to the relatively large gap of this configuration, the flow over the baseline flap separates very near the leading edge. The application of a cove tab delays separation until $1 / 4 \mathrm{c}$ and increases the loading of the main element. With the addition of vortex generators to the flap upper surface, the flow on the flap remains attached and the main element loading is further increased.

The increased loading noted in the pressure distributions corresponds to significant lift increments as shown in Fig. 15. Although the cove tab reduces the stall angle by $3-4 \mathrm{deg}$, the maximum-lift coefficient for the tab with and without vortex generators is increased by 18 and $7 \%$, respectively. An analysis of the pressure distributions with vortex generators (not shown) indicates flow separation below an angle of attack of 8 deg. With the addition of a $0.5 \%$ flap tab, the flow separation is eliminated throughout the entire angle-of-attack range. The maximum-lift coefficient is further increased to 3.32 for this configuration incorporating tabs on both elements and vortex generators on the flap. Relative to the baseline, this is a $23 \%$ increase in maximum lift and almost a 9 deg shift of the lift curve.

Therefore, a nonoptimum flap rigging with a relatively large gap and large-scale flow separation was improved dramatically by the use of lift-enhancing tabs and vortex generators. Relative to configuration 2, which yielded the highest baseline maximum-lift coefficient of 2.82 , the increase in maximum lift still exceeds $17 \%$. However, advanced high-lift systems of modern transports do not generally suffer from serious flow separation as observed here. This suggests that the best application of lift-enhancing tabs to an optimized design would be to increase both flap deflection and gap and use the tabs to avoid flow separation. As demonstrated by this configuration, there is potential for considerable lift enhancement.

The drag polar of Fig. 15 indicates that the pressure drag of the flow separation on the baseline flap is greatly reduced by the presence of the lift-enhancing tabs. With vortex generators, however, the drag reduction at the lower angles of attack is not as great due to the increased skin friction associated with these devices. By adding the flap tab, the flow separation on the flap is eliminated throughout the full angleof-attack range and the reduction in pressure drag offsets the increased skin friction.

Because they reduce separation on the flap and increase aft loading on the main element, both the lift-enhancing tabs and vortex generators increase the nose-down pitching moment (Fig. 16). With each addition to the baseline, the flow over the flap is improved until the pitching moment at maximum lift is approximately double that of the bascline. This trend is typical of the lift-enhancing tab and other trailingedge devices.

The effect of the cove-tab position for the preceding configurations is presented in Fig. 17. These results refer to the application of the cove tab alone (no flap tab or vortex generators). As noted previously, the inboard position refers to the location one tab height forward of the main-element trail- 


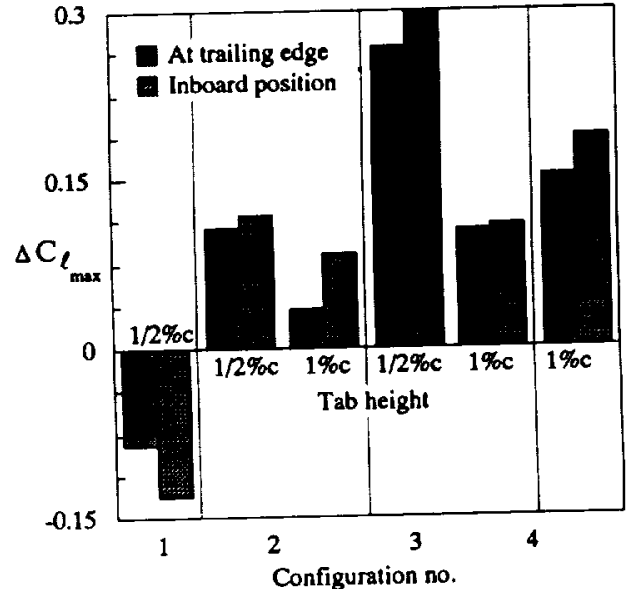

Fig. 17 Effect of cove-tab position on maximum-lift coefficient (configurations 1-4).

ing edge. Except for the 22-deg flap rigging, all configurations indicate that the inboard position to be the most effective. This location greatly simplifies the installation of a hinge for tab deployment. In addition, the $0.5 \% \mathrm{c}$ cove tab yields significantly better performance than the $1 \% c$ tab for a gap on the order of $3 \% c$ (configurations 2 and 3 ). This result is in good agreement with the computed optimum tab height of Ref. 15.

\section{Conclusions}

The application of lift-enhancing tabs and vortex generators to a two-element airfoil was studied experimentally. By reducing or eliminating flow separation on the flap, a tab near the trailing edge of the main element considerably increases lift and reduces drag at moderate to high flap deflections. On a configuration with a flap deflection of $42 \mathrm{deg}$, the cove tab alone increased the maximum lift by $10.3 \%$. However, at low flap deflections where flow separation is absent, the cove tab adversely affects performance by reducing the suction peak on the flap. The tab was tested both at the trailing edge of the main element and at one tab height forward. The inboard position was determined to be the most effective, which simplifies the location of a hinge for tab deployment. The liftenhancing tab located near the flap trailing edge produced an increment in maximum lift from 1 to $4 \%$ for all flap deflections tested. The addition of wishbone vortex generators to the flap eliminated lift-curve hysteresis and reduced flow separation at high flap deflections. Lastly, an off-design case with a large gap yielded the best performance by incorporating lift-enhancing tabs on both elements and vortex generators on the flap. Relative to the optimum baseline tested (no tabs), this configuration provided an increase in maximum lift of $17 \%$.

\section{References}

'Valarezo, W. O., Dominik, C. J., McGhee, R. J., and Goodman, w. L. "High Reynolds Number Configuration Development of a High-Lift Airfoil." High-Lift System Aerodynamics, AGARD-CP515, Banff, Alberta, Canada, 1992, pp. 10.1-10.8.

- Liebeck, R. H. "Design of Subsonic Airfoils for High Lift," Journal of Aircraft, Vol. 15, No. 9, 1978, pp. 547-561.

"Roesch, P., and Vuillet, A., "New Designs for Improved Aerodynamic Stability on Recent Aerospatiale Helicopters," Vertica, Vol. 6. No. 3, 1982, pp. 145-164.

"Neuhart, D. H., and Pendergraft, O. C., Jr., "A Water Tunnel Study of Gurney Flaps," NASA TM-4071, 1988.

5Jang, C. S., Ross, J. C., and Cummings, R. M., "Computational Evaluation of an Airfoil with a Gurney Flap,"Proceedings of the 10th Applied Aerodynamics Conference (Palo Alto, CA), AIAA, WashApplied Aerodynamics C01-809 (AIAA Paper 92-2708)

oStorms, B. L., and Jang, C. S., "Lift Enhancement of an Airfoil Using a Gurney Flap and Vortex Generators," Journal of Aircraft, Vol. 31, No. 3, 1994, pp. 542-547.

${ }^{7}$ Katz, J., and Largman, R.. "Effect of 90 Degree Flap on the Aerodynamics of a Two-Element Airfoil," Journal of Fluids Engineering, Vol. 111, March 1989, pp. 93, 94.

"Katz, J., and Dykstra, L." "Study of an Open-Wheel Racing Car's Rear-Wing Aerodynamics," Society of Automotive Engineers International Congress and Exposition, SAE Paper $89(160) 0$, Detroit, MI. Feb-March 1989.

${ }^{4}$ Ross, J. C. . Storms, B. L., and Carrannanto, P. G., "Lift-Enhancing Tabs on Multi-Element Airfoils," AIAA Paper 93-35(44. Aug. 1993.

"Carrannanto, P. G., Storms, B. L., Ross, J. C., and Cummings, R. M. "Navier-Stokes Analysis of Lift-Enhancing Tabs on MultiElement Airfoils," AIAA Paper 94-(0050, Jan. 1994.

"Wheeler, G. O.. "Low Drag Vortex Generators," U.S. Patent 5058837. 1991.

'Hicks, R. M, and Schairer, E. T., "Effects of Upper Surface Modification on the Aerodynamic Characteristics of the NACA $63_{2}$ 215 Airfoil Section," NASA TM-78503, 1979.

${ }_{13}^{13}$ Schlichting, H. . Boundary-Layer Theory, 7th cd., McGraw-Hill, New York, 1979, pp. 759-761.

${ }_{1+}$ Rogers. S. E., "Progress in High-Lift Aerodynamic Calculations," AIAA Paper 93-0194, Jan. 1993

${ }_{15}$ Carrannanto, P. G. "Navier-Stokes Analysis of Lift-Enhancing Tabs on Multi-Element Airfoils," M.S. Thesis, California Polytechnic State Univ., San Luis Obispo, CA, Aug. 1993. 